\title{
ESTUDO SINTÉTICO DO ABORTAMENTO
}

\section{A. WOLFF NETTO}

1. ${ }^{-}$Assistente de Clínica Obstétrica da Escola Paulista de Medicina

O abortamento é o fracasso da gestação.

$\mathrm{Da}$ - origem etimológica da palavra que, segundo uns provém de "aboriri" (nascer antes do tempo) e segundo outros, de "abortus" (não nascer) - conclue-se que o abortamento é a interrupção da gravidês quando não é viavel ò produto da concepção.

Os vocábulos abortamento e abôrto não são sinônimos. Abortamento é o ato da interrupção da gestação com a expulsão do produto inviável. Abôrto é o produto da concepção expelido no abortamento.

\section{CONCEITO}

Muito se tem discutido quanto à fixação dos limites entre o abortamento e o parto prematuro.

Para Stockel o abortamento é a interrupçã̃o da gestação antes da $28 .^{a}$ semana e parto prematuro, a interrupção entre a $28 .^{a}$ e a $39 .^{a}$ semana. modo :

Segundo Winkel a diferença entre ambos é feitạ do seguinte

$$
\begin{aligned}
& \text { Abortamento - até a } 16 .^{\mathrm{a}} \text { semana. } \\
& \text { Parto imaturo - da } 17^{\mathrm{a}} \text { à } 28 .^{\mathrm{a}} \text { semana. } \\
& \text { Parto prematuro - da } 29 .^{\mathrm{a}} \text { à } 38 .^{\mathrm{a}} \text { semana. } \\
& \text { Parto maduro - da } 39 .^{\mathrm{a}} \text { à } 41 .^{\mathrm{a}} \text { semana. } \\
& \text { Parto sérotino - desta data em diante. }
\end{aligned}
$$

Para Vignes e Barbaro, o abortamento é a expulsão de um embrião isto é, de um produto em fase de organogênese e o parto prematuro, a expulsão de um produto em fase de crescimento.

Mostram estas opiniões quão difícil é, em biologia, dar valor exato às definições $\mathrm{e}$, embora razões didáticas obriguem a matizar os termos, nada se-oporia, em boa lógica, de chamar de abortamento à interrupção da gravidez com embrião ou feto não viavel (interrupção patológica) e de parto, à expulsão do produto em qualquer tempo desde que esteja apto para a vida exterior. 
A classificação e, praticamente a diferença entre parto e abortamento, deve estar, como julga a maioria dos autores, no seu diferente mecanismo de realização. -Ao passo que depois dos 4 mêses; que é quando se considera o ôvo humano como formado de um produto essencial e anexos, a expulsão dos componentes se realizá em tempos e formas diferentes, antes desta data, por corresponder a outras estruturas, a expulsão de todo o conteúdo concepcional do utero realiza-se completamente ou de uma só vez.

Para fins didáticos, entretanto, consideraremos como abortamento a interrupção da gestação antes dos 7 mêses e como parto prematurò, a expulsão do produto antes do $90^{\circ}$ mês.

\section{FREQUÊNCIA}

A frequência do abortamento nunca poderia ser calculada-com exatidão por falta de base precisa para estatística:

As multíparas e as não casadas abortam mais frequentemente do que as primíparas e as casadas.

Fréquentemente os abortamentos muito precoces não chegam ao conhecimento do médico e, às vezes, nem mesmo da mulher que aborta.

Sem falar do abortamento criminoso em proporção crescente nas grandes cidades e mais difícil de se conhecer e classificar pela sua própria natureza - a quantidade de abôrtos - varia com o meio social, com o trabalho físico nas ctasses modestas, infecçốes mal tratadaś, intoxicações de toda espécie e dificuldades econômicas que fazem variar as estatísticas com o ponto de vista em que se coloca o observador.

Aülfeld, Franz, e Küstiner calculam a incidência de 1 abortamento para cada 4 a 6 partos. HEGAR encontrou 1 para 10 partos. DE LEE acha que a relação entre os abortamentos e os partos é de $24 \%$.

Quanto à época da gravidez em que é mais frequente o abortamento, ás estatísticas ainda são mais discordantes.

\section{ETIOLOGIA}

A expulsã́o prematura do produto da concepção tem lugar quando êste morre ou quando a implantação do ôvo, com ou sem a mortẻ do feto, destaca-se prematuramente.

As pesquisas bateriológicas e anatomopatológicas aumentaram o capítulo referente à etiologia do abortamento.

Fundamentalmente dividiremos as causas do abortamento em duas grandes classes. $\mathrm{Na} 1 .^{\mathrm{a}}$ ficarão as causas maternas e na $2 .^{\mathrm{a}}$. as correspondentes ao ôvo, embora, em muitas ocasiões, não šeja fácil determinar com exatidão, á qual delas devemos atribuir, em última análise, a causa do abortamento. Concordam Winkel e Olshausen 
em invocar, na maioria das vêzes a morte do embrião como causa fundamental. Mas de que modo atribuir à 'mãe êste fato? E' a interrogação que em muitos casos fica suspensa.

Para Chauvin e Williams o abortamento é o modo mais frequente de terminação das gestações teratológicas, daquelas em que se a evolução do embrião continuasse êste seria um monstro.

Por outro lado, moléstias febrís podem motivar, pela hipertermia, hipertensão ou toxinas, contrações uterinas e estas, aumentando a tensão sanguínea local que os vasos lesados não suportam, concorrerão para o desencadeamento do abortamento.

Esquematicamente, estudaremos as causas do abortamento dividindo-as em: I - Maternas e II - Fetais.

\section{I - CAUSAS MATERNAS}

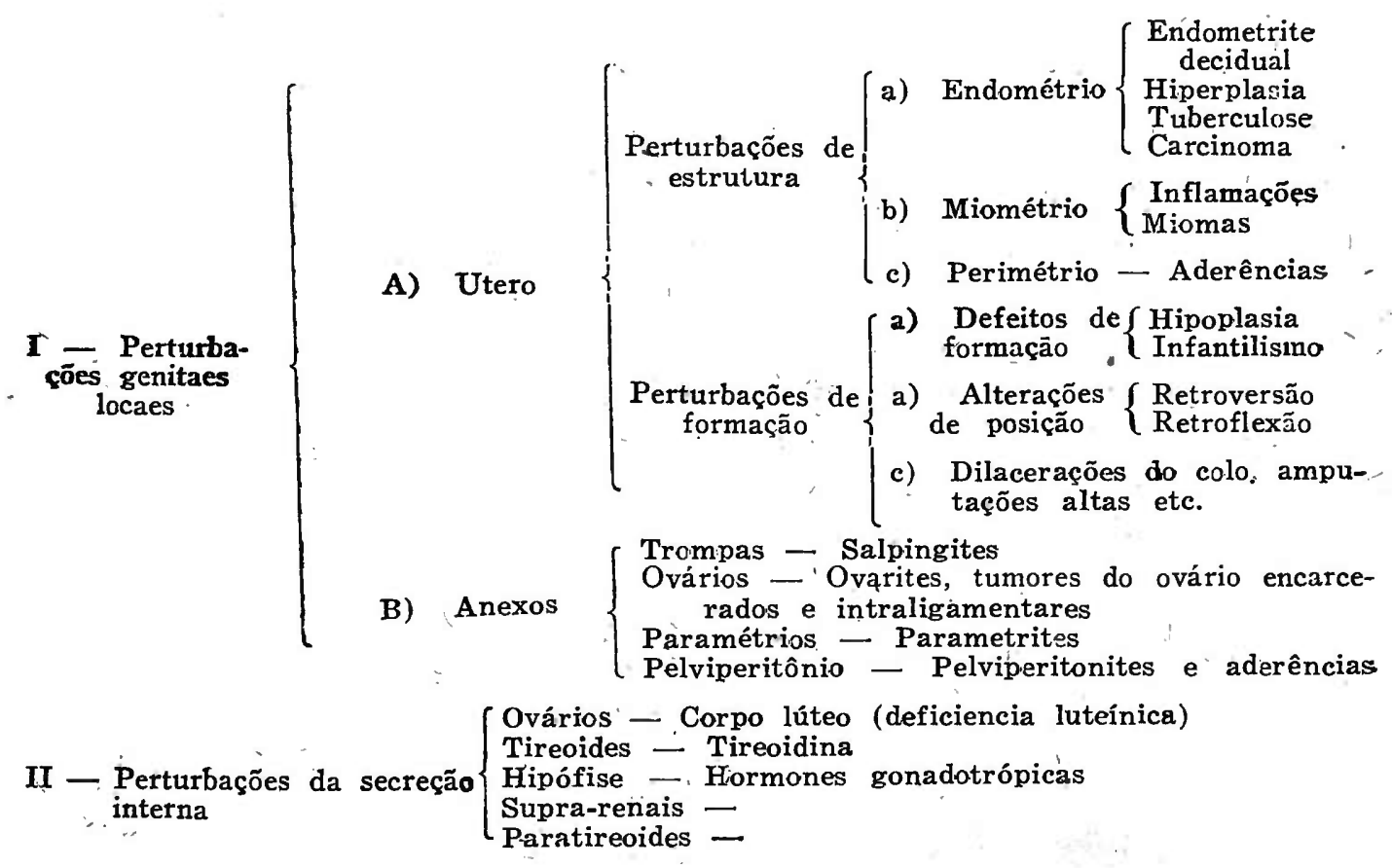




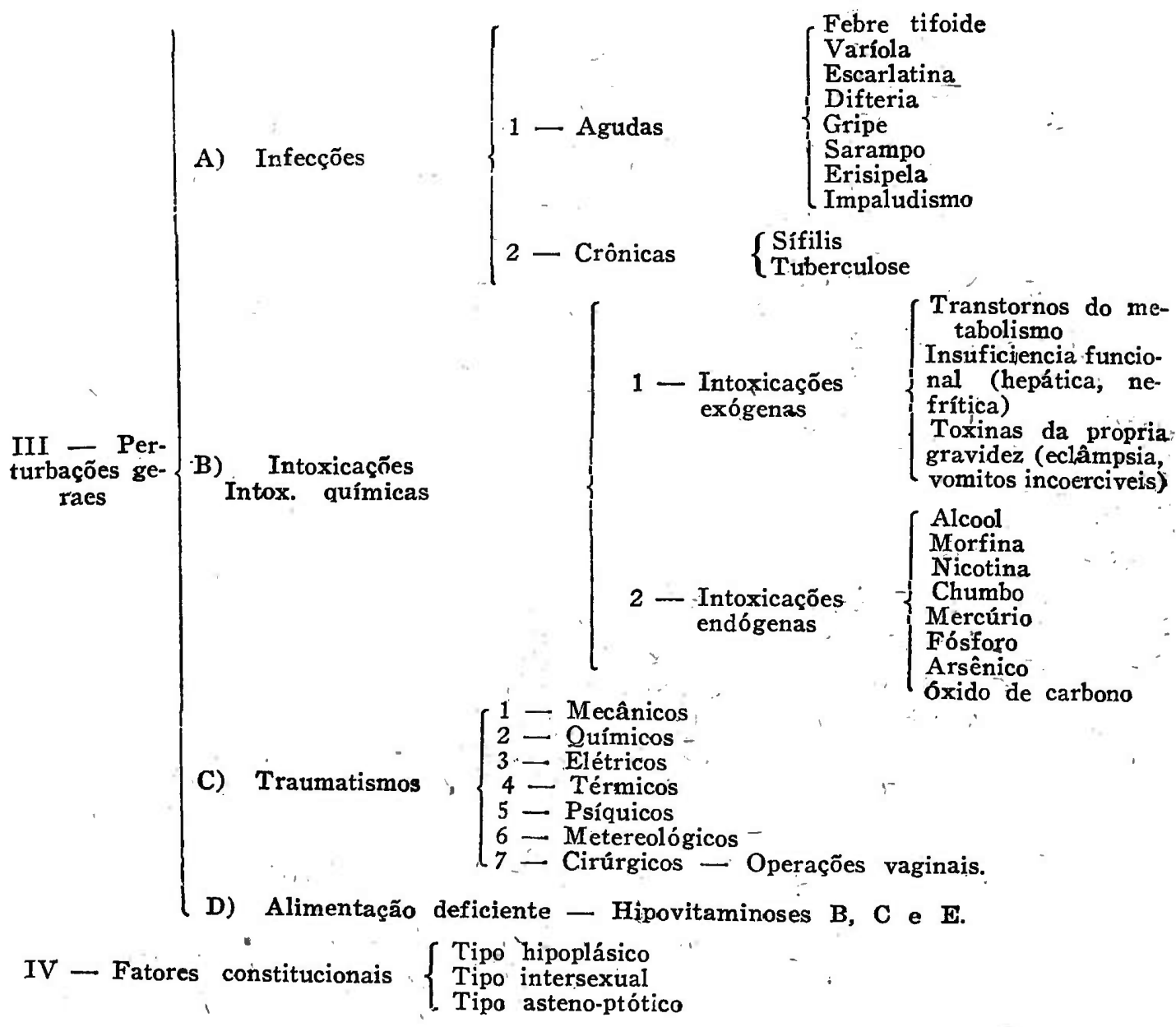

\section{II - CAUSAS OVULARES}

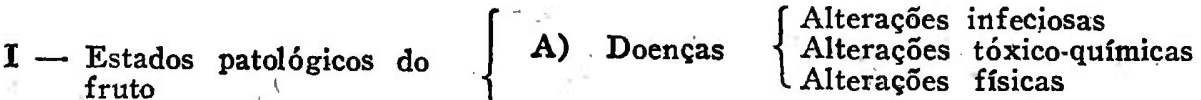

$$
\begin{aligned}
& \text { B) Estados de carência. (Deficiencia alimentar) } \\
& 1 \text { - Cordão umbelică - Anomalias de inserção } \\
& \text { - Hidrâmnio } \\
& 2 \text { - Amnio }\left\{\begin{array}{l}
\text { Oligâmnio } \\
\text { Desenvolvimento extra-corial } \\
\text { do fruto }
\end{array}\right. \\
& \text { Desenvol vimento extra-amnióti- } \\
& \text { co do fruto } \\
& \text { II - Estados patológicos dos } \begin{array}{l}
\text { anexos } \\
3-\text { Cório }
\end{array} \quad\left\{\begin{array}{l}
\text { Mola vesicular } \\
\text { Corioangioma }
\end{array}\right. \\
& 4 \text { - Placenta }\left\{\begin{array}{l}
\text { Infarto } \\
\text { Cisto } \\
\text { Placenta marginal } \\
\text { Placepta }
\end{array}\right. \\
& \text { Placenta circumvalata } \\
& \text { Placenta baixa } \\
& 5 \text { - Decídua - Endométrio (Hidrorrẻa decidual). }
\end{aligned}
$$




\section{CLASSIFICAÇÃO}

Os abortamentos podem ser classificados quanto à idade, quánto ao modo de abortar e quanto à sua evolução clínica.

A classificação pela idade é a seguinte:

Abortamento ov́ular - até 2 mêses.

Abortamento embrionário - até os 4 mêses.

Abortamento fetal - até os 6 "mêses.

Quanto ao modo de abortar varia êste com a constituição do ôvo que há de ser expulso e que é diferente nos vários mêses da gestação.

Antes do $4^{\circ}$ mês, quando ainda não há placenta, mas tão sòmente, a decídua vera, a reflexa, a basal ou serotina, a cório e o âmnio e quando a decídua vera ainda não soldou-se à reflexa; o abortamento se processa em um só tempo. Depois do $4 .^{\circ}$ mès, formada a placenta, não se pode, pròpriamente classificar de abortamento a expulsão do conteúdo uterino, 'que se realiza de modo semelhante ao do parto (modus partus).

Se a gestação interrompe-se antes do $4 .^{\circ}$ mês a expulsão do ôvo se faz em um só tempo e por. 2 mecanismos:

1. - Por desinserção de tôda a decídua verdadeira, como' se desprende a mucósa na dismenorréia mẹmbranácea, quasi mecanicamente, pela hemorragia que a levanta. $\mathrm{E}$ ' o abortamento completo, abortamento em um tempo. (SEITZ), ab. tipico (AhlFeld), ab. perfeito. E' o tipo clássico do ab. expontâneo, sem o perigo de hemorragia, nem de infecção.

2. - Expulsão do ồvo antes da decídua vera que o segue intacta ou não, e'svasiando-se o útero, também de uma só vez.

Depois do $4^{\circ}$ mês a expulsão faz-se, em geral, em 2 tempos. A princípio, é expulso o produto (embrião ou feto) com uma ou várias partes anexiais e, em seguida, as partes restantes.

Do que dissemos poderemos estabelecer a seguinte classificação:

\section{MODOS DE ABORTAMENTO}

A) Abortamento completo ou em um tempo. cídua vera.

2 - O ôvo é expulso antes da vera que o segue imediatamente.

1 - Expulsão do ôvo no sacco da reflexa. Segue-se a vera, num $2 .^{\text {on }}$ tempo.

2 - Expulsão do ôvo ńo cório. Seguem-se a vera e a reflexa.

3. - Expulsão do ôvo no âmnio. Seguem-se a vera, reflexa e o cório.

4 - Expulsão do fructo isolado. Seguem-se a vera, a reflexa, o cório e o âmnio (modus partus). 
Quanto à evolução clínica, o abortamento pode ser classificado do seguinte modo:

A) Abortamento evitável ou iminente - Caraterizado por perdas sanguíneas discretas, precedidas de dôres hipogástricas semelhantes às da algomenorréia homocólica. $O$ exame pelo tocar revela a inexistência de dilatação do colo (orifício interno nas multiparas), De regra o repouso, os sedativos, a vitamina $\mathrm{E}$ e as hormones do corpo lúteo evitam 'o abortamento e a gestação evolue normalmente até o têrmo. Outras vezes, entretanto, o abortamento se processa.

B) Abortamento inevitável - As dôres são mais intensas e a hemorragia maior, princípalmente quando o féto está vivo e os cotilédones se desprendem com lentidão. Pelo toque observam-se fenômenos semelhantes aos da evolução clínica do parto, como sejam, o esvaecimento e a dilatação do colo do útero.

O abortamento inevitável pode ser febril ou afebril. Considera-se como abortamento febril aquele em que a temperatura vae além de 37,2. Até 37,2 o abortamento é afebril, pois a referida temperatura é considerada como de reabsorpção.

No abortamento completo ou em um só tempo e afebril a hemorragia é mínima e ao abôrto, seguem-se perdas lóquiaes e "subida do "leite", em intensidade menor do que no parto.

No abortamento incompleto ficam rétidos restos ovulares que saem depois desintegrados e com os lóquios. Taes restos ovulares permanecendo retidos no útero podem sofrer transformações originando os polipos placentários e tumores malignos ou benignos.

O abortamento febril é comumente dividido em ovular e para-ovular Ovular quando a penetração microbiana se dá nos tecidos ovulares e para-ovular quando os germens se localizam nos tecidos vizinhos ao ôvo.

O abortamento febril ainda pode ser pútrido ou séptico.

No abortamento pútrido a febre aparece tardiamente com a putrefação dos tecidos ovulares. $\mathrm{O}$ colo uterino se apresenta dilatado e o prognóstico é bom.

No abortamento séptico a febre é alta desde o início e são frequentes os calafrios. O colo se apresenta fechado e é frequente, também, a hemorragia.

O abortamento febril, quanto à sua evolução deve ser dividido, ainda em complicado e não complicado.

No abortamento febril não complicado o processo infeccioso resume-se ao ôvo e à região circunvizinha. A mortalidade é de 2,7\%. Pode apresentar bacteremia passageira."

O abortamento febril é complicado quando o processo infeccioso ultrapassa o útero propagando-se pelas vias limfática e sanguínea ou por continuidade e produzindo a parametrite, a pelviperitonitc, a 
anexite, a pioemia e a septicemia.- Neste caso a mortalidade é alta, atingindo $47,5 \%$.

\section{SYMPTOMATOLOGIA, DIAGNÓSTICO E TRATAMENTO}

O abortamento iminente é caraterizado pelos seguintes sintomas: após amenorréia, dôres hipogástricas seguidas de hemorragia discreta. $\mathrm{O}$ diagnóstico é feito pela verificação dêsses sintomas e pelo tocar que revela o útero grávido, sem dilatação do colo. O tratamento indicado é o repouso no leito, opiaceos (ópio, clister de láudano, etc.) e a progesterona.

$\mathrm{O}$ abortamento inevitável apresenta sintomatologia e tratamento diferènte conforme é apirético ou febril. No apirético, devemos considerar o completo e o incompleto. No primeiro, as dôres são intensas e a hemorragia é pequena, apresentando-se o colo uterino dilatado e esvaecido, e, o que é importante, a hemorragia cessa logo após a expulsã̉o do abôrto. No segundo, as dôres são mais fortes e a hemorragia que é mantida pela retenção dos restos ovulares póde ter tal intensidade que chegue a apresentar o caráter dramático. Verifica-se pelo toque combinado o colo esvaecido, dilatado e o útero mole, cheio de restos ovulares ou placentários. No primeiro caso a pituitrina e a bolsá de gelo no ventre resolvem o tratamento e no segundo, necessário se torna além dó gelo e do ocitóxico a curetagem. où a curagem.

Se o abortamento inevitável é febril, seja na variedade pútrido ou séptico, com febre, taquicardia, hemorragia, dôres hipogástricas, "colo dilatado e útero cheio de restos ovulares ou placentários infectados, o tratamento consiste no levantamento do estado geral da paciente, método de WINTER e administração das sulfanilamidas.

\section{PROGNÓSTICO}

O prognóstico varia conforme o tipo de abortamento sendo mais grave no febril séptico, principalmente, se complicado.

\section{COMPLICAÇÕES}

Dentre as complicações do abortamento devemos salientar as infecciosas e as de retenção ovular. 


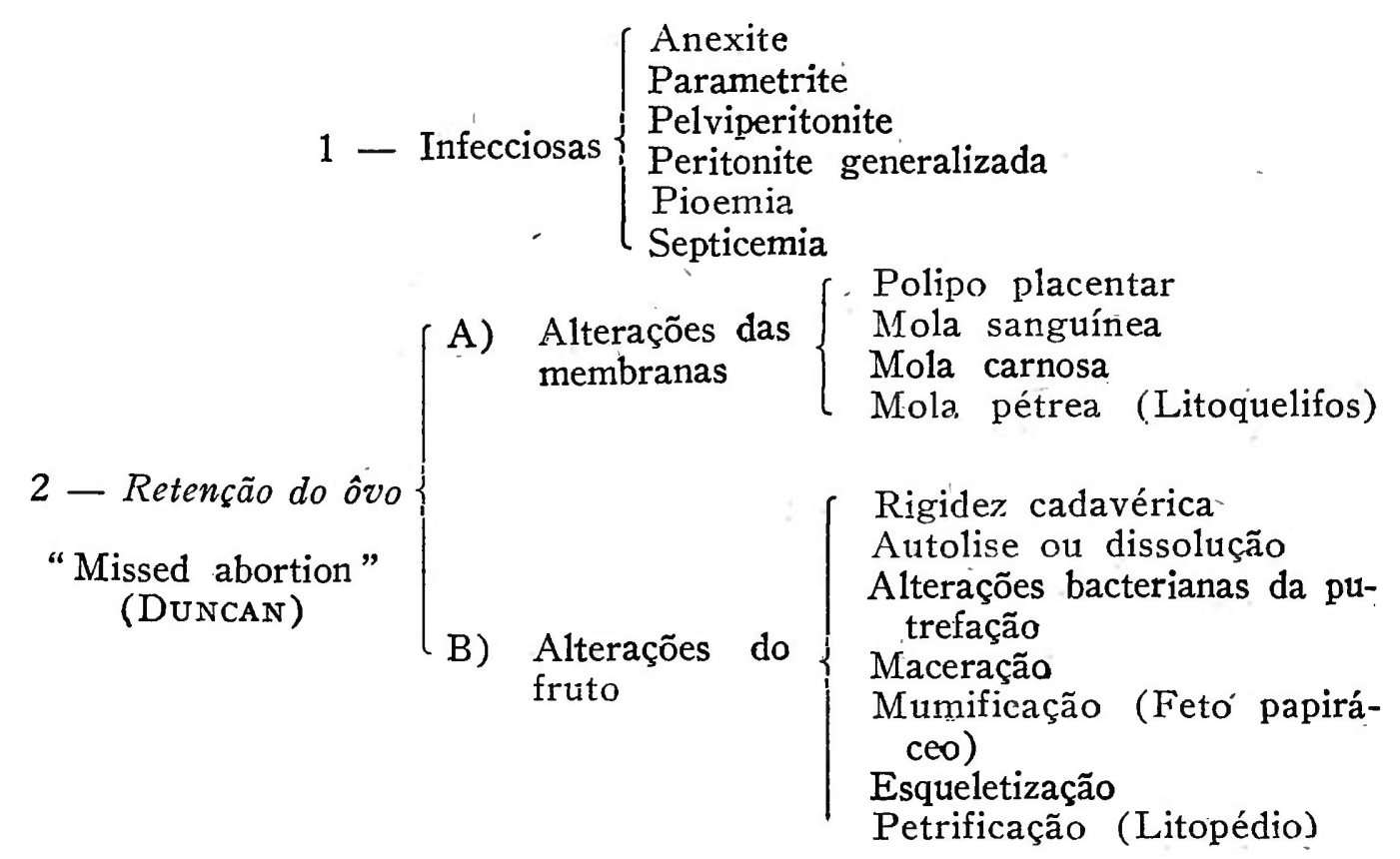

CARDIOSCLEROL TONICO CARDIACO ATOXICO

HIPERTENÇÃO ARTERIAL. - MIOCARDITES - ARTERIOESCLEROSE A base de Viscum album - Cactus grandiflora - Cratoegus - Kola - Scila - Rodanato de Potassa

Amostras e literaturas a disposição dos srs. Medicos

CAIX'A, 4500

\section{INSTITUTO CHIMORGAN}

